\title{
Coagulation-Flocculation Treatment for Naphthol Green Band Flour Wastewater
}

\author{
Bukola M. ADESANMI ${ }^{1}$ | Yung-Tse HUNG ${ }^{1} * \mid$ Howard H. PAUL ${ }^{2}$
}

${ }^{1}$ Department of Civil and Environmental Engineering, Cleveland State University

${ }^{2}$ Department of Information Systems, Cleveland State University

To Cite this Article

Bukola M. ADESANMI, Yung-Tse HUNG and Howard H. PAUL, "Coagulation-FlocculationTreatmentfor Naphthol Green Band Flour Wastewater”, International Journal for Modern Trends in Science and Technology, 6(12): 190-197, 2020.

\section{Article Info}

Received on 10-November-2020, Revised on 30-November-2020, Accepted on 04-December-2020, Published on 08-December-2020.

\section{ABSTRACT}

The interference of synthetic dye in the water bodies and environment poses a risk to both human and environmental health. Due to the recalcitrant nature of dye and presence of many other pollutants in industrial wastewater, efficient method of treatment of industrial effluent is required to address the lingering problem over the years. To address this major concern, experimental was carried out on synthetic dye and flour wastewater treatment by coagulation-flocculation while varying operating parameters (dosage, concentration, coagulant type etc.). The effectiveness of coagulation-flocculation process for the removal of Naphthol Green B in a mixture of dye wastewater and flour wastewater at different concentrations (50 ppm, $100 \mathrm{ppm}, 150 \mathrm{ppm}, 200 \mathrm{ppm}$ ) was investigated. Using 3 coagulant ( $\mathrm{FeCl}_{3}, \mathrm{FeSO}_{4}$ and $\left.\mathrm{Al}_{2}\left(\mathrm{SO}_{4}\right)_{3}\right)$, color removal efficiency was also investigated. The effectiveness of the coagulation process was measured for transmittance and absorbance as indices using UV-Vis Spectrophotometer. Also, the total organic carbon (TOC) was measured. Transmittance and absorbance values of $99.6 \%$ and 0.001 respectively were achieved post treatment. Ferric Chloride and Aluminum Sulfate gave better results than Ferrous Sulfate which gave the poorest transmittance and absorbance values indicating reduced color removal efficiency. The results of this study revealed that coagulation process is an efficient preliminary treatment for appreciable suspended particles and color removal from dye wastewater. It also showed the impact of coagulant dosage, dye strength and combined wastewater samples on the removal efficiency and resulting effluent quality.

KEYWORDS: Dye, coagulation, flocculation, color removal, wastewater, transmittance, absorbance

\section{INTRODUCTION}

Industrialization is one of the essential factors for proper economic development, but the good management and disposal of industrial effluent is important for solid environmental health. Various industries including the food, plastics, paper, pharmaceutical, cosmetics, and textile use dye to color their product. Based on the wide use of dye, it is a content of effluent produced during various industrial processes. Textile production and yarn processing sector contribute the largest amount of hazardous chemical wastewater, accounting for nearly $22 \%$ of the total volume of industrial effluent produced (Tang \&Zaini, 2020). In the early days, natural dyes were used but with the advent of civilization, demand for large scale use of dye increased. The increase in demand brought about the introduction of synthetic dyes to balance demand and supply. There are more than 100,000 type of commercially synthetic dye produced annually to the tune of $7 \times 10^{5}$ metric tons(Abhiram et al, 2020). About $10-15 \%$ of this synthetic dyeis lost within various processes of textile production" (Mohamed \&Ahmed, 2017). Without the proper 
investigation of the negative effect of the synthetic dye to the environment, rather focusing on the huge profit for industries, more companies produced and used the synthetic dye. Over the last decades, the use of synthetic dyes in various industrial processes has gained huge acceptance. This response has brought about an exponential increase in the discharge industrial effluents containing dye into the soil and water bodies (Mohamed \&Ahmed, 2017). As a result, the environment has been polluted with dyes which are not easily degradable. The recalcitrant and carcinogenic nature of modern synthetic dyes has made the environmental regulations for their disposal stricter and more restrictive.

Wastewater is water discharged from the community, commercial properties, industry, agricultural processes after it has been used in a variety of applications and that contained contaminants that make it unsuitable for most uses without treatment. Industries particularly textile, food, paper, and pulp manufacturing are known to consume large volumes of water during their daily operations. They therefore contribute a pro-rata amount of wastewater as effluent that is characteristic of their raw material properties. Disposal of untreated wastewater leading to color pollution in the water bodies is a major problem. Although considerable research has been done to modify the dying process to achieve a better fixation of the dyestuffs onto the substrate (Sathiyamoorthy et al, 2012). Too often, carcinogenic compound produced by anaerobic degradation of dye end up in the food chain (Chen et al, 2018). Furthermore, highly colored wastewaters potentially block sunlight and oxygen from penetrating into the ocean. These two are essential for aquatic lives. Also, because of increasing environmental awareness and stricter regulations various treatment technologies for dye wastewater has been developed (Chen et al, 2018). Over the years, dyes from wastewater have been treated by physical, chemical, and biological methods, such as coagulation, adsorption, membrane filtration, chemical precipitation, advanced oxidation with light or electricity, and biological degradation with microorganisms [5]. Biochemical oxygen demand (BOD) and suspended solids (TSS) are effectively removed using these processes but are not fantastic alternatives for color removal from wastewater [Aziz et al, 2007 and BasavaRao\&MaohanRao, 2006). The two major methods for decolorization of wastewater are destruction of dye molecules (e.g., chemical oxidation and bio-oxidation) and separation of dyes from water (e.g., coagulation/flocculation, sand filtration and membrane separation) (Zahrim\&Hilal, 2013). Although the separation method such as adsorption is effective and widely accepted, the destruction methods that involve the dye change through chemical oxidation, photo-catalysis and biodegradation require large amount energy to breakdown light stable, oxidizable and microbial degradable dye molecules (Minke\&Rott ,1999 and Booth et al, 2000). "To treat industrial wastewater containing dye, various biological, physical, and chemical process methods have been used but most of this treatment methods are usually very expensive and environmentally unsafe" (Nigam, et al, 2000 and,Rauf, et al, 2007). A good and popular example involves treatment using powdered activated carbon and activated bentonites (Pala, 2002 and Yavuz\&Aydin, 2002). Even so, the use has been restricted with some dyes because of the huge quantity of sludge produced and the low efficiency (Pearce et al, 2003). A rapid and effective method of colour treatment involves using ozone, but some of the other methods employed do not give satisfactory results especially for certain dispersed dyes (Aksu, 2005). "Physical-chemical flocculation with metal hydroxides aided by polymer flocculants is another treatment method popularly used for colored effluents" (Bako, 2014). A method more practically accepted is the use of premixed polyelectrolyte complexes brought about by aqueous solutions of polycation and polyanions reacting together (Petzold. Et al, 1998) Through hydrophobic and electrostatic interaction forces, disperse dyes can effectively be bonded over large distances due to their size and structure by such complex particles (Buchhammer, et al, 2001)However, it is essential to apply other flocculation principles due to the incomparably small size of dye molecules and their aggregates in relation with such inorganic particles, which are sometimes uncharged. Many of the dye wastewater methods of treatment are not cheap and have low purification efficiency.

Coagulation treatment has been effective in removing color especially for wastewaters, containing dissolvable solids. As far back as the 19th century, coagulation has been known for effluent treatment through the utilization of a combination of lime with calcium chloride or magnesium (Muruganandam et al,2007). In the sequence of treatment, coagulation and flocculation process is succeeded by sedimentation, filtration, and disinfection, in the 
primary stage and followed by chlorination. This water treatment method is universally employed by industries before water distribution to the final consumers. In normal water treatment processes, various types of coagulants are been used for making the water suitable for consumer consumption (Matilainen et al, 2005)]. These coagulants can be classified as biological coagulants, inorganic coagulants, and synthetic polymers (binti\&Nithyanandam 2013, Renault et al 2009). Coagulation is a process simple to operate, effective for wastewater treatment and involves low capital cost (Liang et al, 2014).

Based on this background,this study is carried out to evaluate the extent of color removal from textile and flour wastewater by coagulation-flocculation treatment. This article reports the methods, conditions, and result of the experiment.

\section{Coagulation and flocculation}

Coagulation treatment is a method involving the use of certain chemicals called coagulants, traditionally alum (aluminum sulfate $\left.\mathrm{Al}_{2}(\mathrm{SO} 4)_{3}\right)$, ferric chloride $\left(\mathrm{FeCl}_{3}\right)$, or ferrous sulfate $\left(\mathrm{FeSO}_{4}\right)$ to neutralize charges and form gelatinous large mass of particles which when settled can be trapped by filtration (Tzoupanos\&Zouboulis., 2008) It is the application of chemical substance called coagulant to enable the agglomeration and settling of suspended and colloidal particles in wastewater. Due to the relatively low density of suspended and colloidal particles, they do not settle under gravity (Tzoupanos\&Zouboulis., 2008). Also, because they have a negative charge repelling each other, cannot they be removed by physical processes such as sedimentation.

Theoretically, particles in water are negatively (anionic) and are neutralized by the positive charges (cations) making the sample particles stick together to form larger particles of heavier density (flocs) by slow agitation which can easily be removed by filtration. Trivalent cations are more effective as coagulants than their divalent peer, meaning that the higher the number of cations present in the coagulant, the stronger it is. It is not uncommon to combine organic coagulant such as poly-DADMAC with other inorganic coagulants (alum, $\mathrm{Fe}_{2} \mathrm{SO}_{4}, \mathrm{FeCl}_{3}$, etc.) as a single coagulant in the treatment process for effective result. Both inorganic and organic coagulants have their advantage and disadvantage. Inorganic coagulants are limited in application because they are $\mathrm{pH}$ sensitive while Organic coagulants have complex structure which aid the coagulation process and their sensitivity to $\mathrm{pH}$ insensitive is reduced. Flocculation is the method of stirring and agitation of treated sample to facilitate agglomeration and formation of particle into large masses filtered from solutions. This is the process in which the smaller particles merge to form bigger ones. The extent and rate of particles aggregation and breakup is dependent on applied velocity gradient and time of flocculation.

\section{Dye wastewater quality parameters}

Dye and Flour wastewater quality is described in spectrophotometry using two unique parameters namely, Transmittance and absorbance. Although a spectrophotometer can display both transmittance and absorbance of a sample, transmittance and absorbance values from spectrophotometry measurement are related by the equation (Buchhammer et al,2001):

$$
A=\log _{10}(1 / T)
$$

To measure coloration in relation to amount of absorbed light at different wavelength, the Beer-Lambert Law applies:

A - absorbance

$$
A=\square \lambda \max L C
$$

T- transmittance

C - concentration $(\mathrm{mg} / \mathrm{l})$

$\square_{\lambda \max }$ molar extinction of coefficient of the colored solution at maximum wavelegth

L- distance traveled by the light beam through the solution $(\mathrm{cm})$

\section{Analysis of Total Organic Carbon}

Total organic carbon measures the quantity of organic compounds present in water. Some of this organic contaminant in water do not affect the characteristic color of the water hence cannot be detected visually unlike dye. To detect and measure the quantity of this organic contaminant, TOC -L SHIMADZU was used by injection of samples through thermal catalytic oxidation at $680^{\circ} \mathrm{C}$.

Total organic carbon can also be called NPOC (Non-purge-able organic carbon)and refers to organic carbon contained in a sample in the non-volatile state. This is because the sample is acidified and purged with carbon free air or nitrogen which helps to eliminate the inorganic carbon as carbon dioxide, oxidize and measure the remaining non-purge-able carbon. NPOC is calculated as 
NPOC $(\mathrm{TOC})=\mathrm{TC}-\mathrm{IC}$

$\mathrm{TC}$ - total carbon in the sample

IC - total inorganic carbon

\section{MATERIALS AND METHODOLOGY}

The combined naphthol green $\mathrm{b}$ and flour wastewater was prepared in the laboratory using distilled water for standard solutions.Aluminum Sulfate, Anhydrous Ferric Chloride and Ferrous Sulfate were used as coagulants to investigate the color removal of naphthol green $B$ dye by coagulation treatment. Equipment used to carry out the experiment included spectrophotometer (Carolina \#65-3303), weighing balance (Mettler Toledo), open air platform shaker (Innova 2300) and TOC analyzer (Shimadzu 5050).

\section{Naphthol Green B}

The C.I. (Color Index) number is 10020 with C.I. name is acid green 1. It comes under the class of nitroso with acidic ionization and is very soluble in aqueous solution. Its molecular formula is $\left(\mathrm{C}_{10} \mathrm{H}_{5} \mathrm{NO}_{5} \mathrm{SNa}\right)_{3} \mathrm{Fe}$ with formula weight 878.79. This commercial dye is a lake, in which the mordant metal is ferric iron.It may undergo a photo redox reaction in analogy to numerous other $\mathrm{Fe} 3+$ complexesbecause it isan iron(III) compound.However, the iron appears to play no part in staining tissues. The unlocked dye is Naphthol green Y, C.I. 10005 i.e. that it is a sodium salt of Naphthol green Y. It attaches to tissues is through the sulphonic group. The dye is therefore an acid dye, but it is rarely used for staining tissues [17].

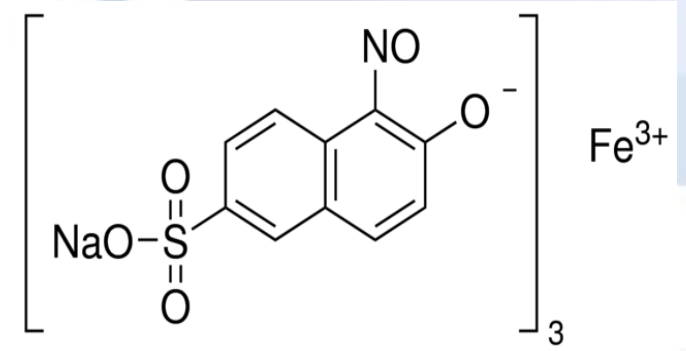

Figure 1 The Chemical Structure of Naphthol Green B (Li et al, 2017)

\section{Flour wastewater}

There are different type of flour including wheat flour, cassava flour, sweet potato flour and potato flour. Flours are important raw materials for different manufacturing and food processing industries. Flour fall under the starch class of food and starch wastewater generated from the industries such as food, cosmetic, pharmaceutical, medicine, chemical, papermaking, textile, detergents are difficult to treat effectively(Fatah\&Hawash, 2018). This is because they have high COD and starch is generally difficult to decompose by microorganism. For this experiment,wheat flour wastewater was prepared from flour bought from the grocery store.

\section{Method}

A weighing balance with the precision of $\pm 0.01 \mathrm{~g}$ is used for weighing the materials: dyes and flour waste. From the weighed materials, dye, and flour wastewater stock solution of $1 \mathrm{~L}$ is prepared and stirred thoroughly with a glass stirrer. From the two mother samples of dye and flour wastewater, desired quantity of combined dye and flour wastewater is prepared. The combined dye and flour wastewater are treated with the coagulants and then the samples bottle is placed in a mechanical shaker and mixed vigorously for 1 minute at $100 \mathrm{rev} / \mathrm{min}$ (fast shake) followed by 30 minutes of slow shaking at $30 \mathrm{rev} / \mathrm{min}$. The solution kept still to allow settle for $60 \mathrm{~min}$ and so that the coalescence could precipitate. This the sedimentation phase.

The spectrometer warmed up for $30 \mathrm{~min}$ upon turning on and then the wavelength set. The spectrometer was then calibrated by filling a sample vial with distilled water. The distilled water sample is used as reference because it has 0 absorbance and 100\% transmittance(Madiraju et al, 2018). This followed by placing the treated sample in the spectrometer to be analyzed, transmittance and absorbance readings were taken,andsupernatant was measured for TOC removal. The same procedure is repeated for different dye concentrations. Run protocol of combined Naphthol Green B and flour wastewater was developed based on literature as shown in Table 1.

Table 1. Run protocol of combined Naphthol Green B and flour wastewater treated with coagulants

\begin{tabular}{cccc}
\hline $\begin{array}{c}\text { Run } \\
\text { Orde } \\
r\end{array}$ & $\begin{array}{c}\text { Dye } \\
\text { Concentration(mg/ } \\
1)\end{array}$ & $\begin{array}{c}\text { Flour } \\
\text { Concentration(mg/ } /\end{array}$ & $\begin{array}{c}\text { Coagulan } \\
\text { t Dosage } \\
(\mathrm{mg} / 1)\end{array}$ \\
\hline 1 & 50 & 0 & 0 \\
2 & 50 & 100 & 0 \\
3 & 50 & 200 & 0 \\
4 & 50 & 300 & 0 \\
5 & 50 & 400 & 0 \\
6 & 50 & 0 & 30 \\
\hline
\end{tabular}




\begin{tabular}{cccc}
\hline 7 & 50 & 100 & 30 \\
8 & 50 & 200 & 30 \\
9 & 50 & 300 & 30 \\
10 & 50 & 400 & 30 \\
11 & 50 & 0 & 60 \\
12 & 50 & 100 & 60 \\
13 & 50 & 200 & 60 \\
14 & 50 & 300 & 60 \\
15 & 50 & 400 & 60 \\
16 & 50 & 0 & 90 \\
17 & 50 & 100 & 90 \\
18 & 50 & 200 & 90 \\
19 & 50 & 300 & 90 \\
20 & 50 & 400 & 90 \\
21 & 50 & 0 & 120 \\
22 & 50 & 100 & 120 \\
23 & 50 & 200 & 120 \\
24 & 50 & 300 & 120 \\
25 & 50 & 400 & 120 \\
26 & 50 & 0 & 150 \\
27 & 50 & 100 & 150 \\
28 & 50 & 200 & 150 \\
29 & 50 & 300 & 150 \\
30 & 50 & 400 & 150 \\
\hline
\end{tabular}

\section{RESULTS AND DISCUSSION}

The present investigation was performed using conventional coagulants to evaluate their suitability for treatment of dye and flour effluent. To represent the performance of aluminum sulfate, anhydrous ferric chloride and ferrous sulfate coagulants on different dye and flour concentration, the results have been tabulated for effective comparison. Coagulant dosage of 30,60, 90,120 and $150 \mathrm{mg} / 1$ were introduced to dye wastewater of concentration 50,100, 120 and 200 $\mathrm{mg} / 1$ singly and in the presence of flour wastewater of concentration $100,200,300$ and $400 \mathrm{mg} / 1$.

\section{Influence of dye and flour concentration}

The decolorization efficiency and appreciable turbidity removal for dye and flour wastewater is influenced by dye and flour concentration within the sample. The highest transmittance and lowest absorbance value were observed at low dye and low flour concentration between $50 \mathrm{ppm}-100 \mathrm{ppm}$. Meanwhile, the lowest transmittance and highest absorbance value were seen at high dye and flour concentration between 150 ppm -200 ppm. Hence the overall trend observed was that the increase in dye and flour concentration decreases the transmittance and increases the absorbance translating to reduction in the effectiveness of the coagulation-flocculation treatment.
Table 2. Dye Concentration Values for Naphthol Green B at 40mg/L Ferric Chloride

\begin{tabular}{ccc}
$\begin{array}{c}\text { Dye } \\
\text { Concentration(mg/L) }\end{array}$ & $\begin{array}{c}\text { Absor } \\
\text { bance }\end{array}$ & $\begin{array}{c}\text { Transmi } \\
\text { ttance }(\%)\end{array}$ \\
\hline 0 & 0 & 100 \\
50 & 0.164 & 68.0 \\
100 & 0.287 & 51.5 \\
150 & 0.393 & 40.5 \\
200 & 1.141 & 7.2 \\
\hline
\end{tabular}

\section{Influence of coagulant dosage on dye and flour wastewater}

Coagulant dosage was one of the most important parameters considered in determining the optimum conditions for dye and flour removal from the sample wastewater. Using five different dosage $(30,60,90,120,150 \mathrm{mg} / \mathrm{l})$ of the three coagulant, the study showed that increase in coagulant dosage resulted in increase of charge neutralization, settling, and fading of color in the sample solution. This was observable in the corresponding increase in transmittance values and decrease in absorbance values. An increase in coagulant dose improves color and turbidity removaland TOC removalbetween $18 \%$ $78 \%$ regardless of coagulant. This is illustrated in Table 3 and Figure 2.

Table 3. Influence of Ferric Chloride Dosage on 50mg/L Dye and $100 \mathrm{mg} / \mathrm{L}$ Flour concentration

\begin{tabular}{cccc}
\hline $\begin{array}{c}\text { Dye } \\
\begin{array}{c}\text { Concentration(m } \\
\text { g/L) }\end{array}\end{array}$ & $\begin{array}{c}\text { Flour } \\
\text { Concentration(m } \\
\text { g/L) }\end{array}$ & $\begin{array}{c}\text { Coagula } \\
\text { nt Dose } \\
(\mathrm{mg} / \mathrm{L})\end{array}$ & $\begin{array}{c}\text { Transmitta } \\
\text { nce }(\%)\end{array}$ \\
\hline 50 & 100 & 0 & 69.8 \\
50 & 100 & 30 & 81.1 \\
50 & 100 & 60 & 87.3 \\
50 & 100 & 90 & 92.2 \\
50 & 100 & 120 & 97.2 \\
50 & 100 & 150 & 99.3 \\
\hline
\end{tabular}




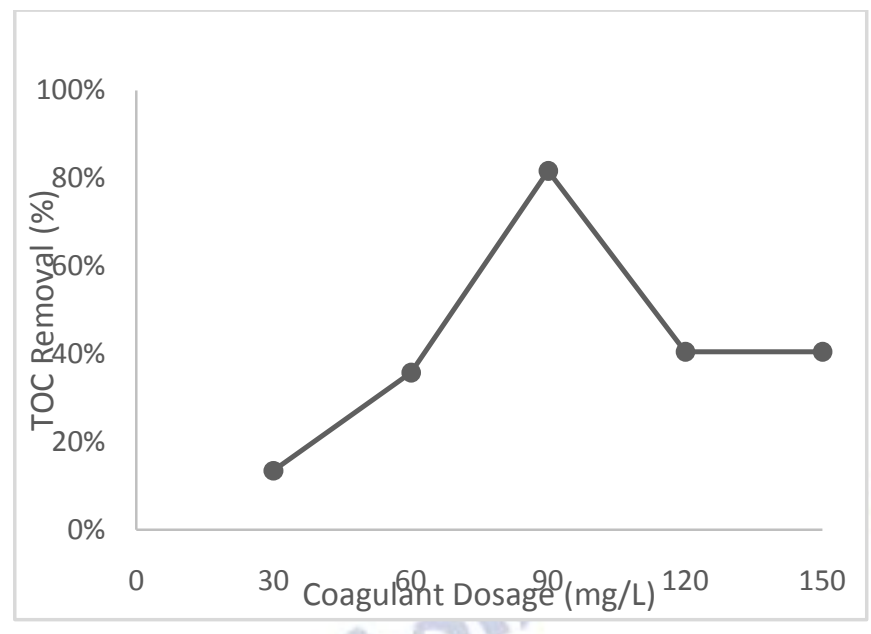

Figure 2 Influence of coagulant dosage on TOC removal forcombineddye and flour wastewater at $100 \mathrm{ppm}$

\section{Influence of coagulant type and valence}

From the results, it was observed that the type of coagulant has an impact on color and turbidity removal. Although all three coagulants provided a high color removal efficiency, ferric chloride was the most effective coagulant in decolorizing Naphthol Green B dye and achieving appreciable turbidity removal. The best color and turbidity removal wereobserved with ferric chloride at a dosage of $150 \mathrm{mg} / 1$ with transmittance of 99.6\%.Also, a good color removal withAluminum sulphate coagulant with transmittance value of $99.2 \%$ at a dosage of $150 \mathrm{mg} / 1$ was observed. Ferrous sulphate had the least impact on sample wastewater with a transmittance value of $90.7 \%$. The resulting transmittance value and effectiveness of the coagulants is connected to reduced potency of +2 valence, exhibited by Ferrous Sulfate as compared to +3 exhibited by Ferric Chloride and Aluminum Sulfate.

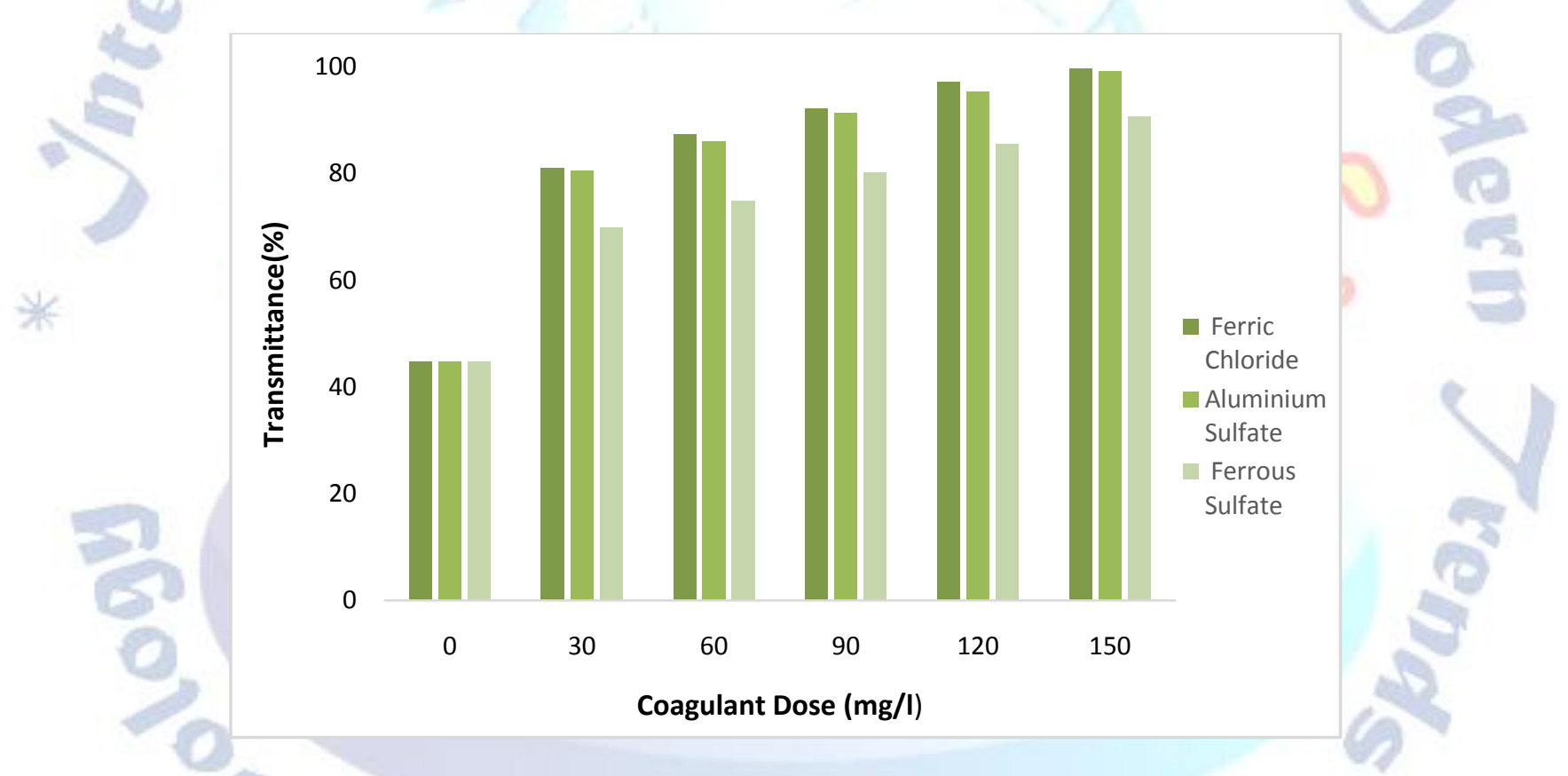

Figure 3. Naphthol Green B, 50 ppm and 100 ppm Flour Treated with Different Coagulants

\section{Influence of dye strength on combined wastewater}

Applying aluminum sulfate at low dye concentration $(50 \mathrm{mg} / \mathrm{l})$ and low flour concentration $(100 \mathrm{mg} / \mathrm{l})$ which represent the low strength sample, the best values for absorbance and transmittance of 0.010 and $95.3 \%$ wasobserved, respectively. This indicated that the coagulants were able to effect charge neutralization and subsequent settling relatively easily because of the combined low dye strength. The dilution effect of the low strength flourwastewater also contributed to the increased transmittance and reduced absorbance values accordingly.
The medium dye concentration (100 mg/l) and medium flour concentration (200 mg/l) which represent the medium strength samplegave comparatively lower transmittance and corresponding higher absorbance values than the low strength sample. Transmittance and absorbance values were seen to be $90.1 \%$ and 0.048 , respectively. The least values of $78.9 \%$ and 0.067 were observed for high strength sample (high dye concentration-high flourconcentration) as summarized in Table 4. 
Table 4. Effect of Aluminum sulfate dosage on 100mg/L Naphthol Green B

\begin{tabular}{ccccc}
\hline $\begin{array}{c}\text { Dye } \\
\text { concentrat } \\
\text { ion }(\mathrm{mg} / \mathrm{L})\end{array}$ & $\begin{array}{c}\text { Flour } \\
\text { wastewater } \\
\text { Concentration } \\
\mathrm{mg} / \mathrm{L})\end{array}$ & $\begin{array}{c}\mathrm{Al}_{2}(\mathrm{SO} \\
4)_{3} \\
\mathrm{Dosag} \\
\mathrm{e} \\
(\mathrm{mg} / \mathrm{L})\end{array}$ & $\begin{array}{c}\text { Transmitta } \\
\text { nce }(\%)\end{array}$ & $\begin{array}{c}\text { Streng } \\
\text { th }\end{array}$ \\
\hline 50 & 0 & 120 & 92.6 & $\begin{array}{c}\text { Low } \\
\text { Mediu } \\
\mathrm{m}\end{array}$ \\
100 & 0 & 120 & 88.1 & $\begin{array}{c}\text { High } \\
150\end{array}$ \\
50 & 0 & 120 & 74.8 & Low \\
100 & 100 & 120 & 95.3 & Mediu \\
150 & 200 & 120 & 90.1 & $\mathrm{~m}$ \\
& 100 & 120 & 78.9 & High \\
\hline
\end{tabular}

\section{CONCLUSION}

Synthetic dye and flour wastewater were successfully prepared using distilled water for dilution and treated by coagulation/flocculation process. The study has shown that dye and flour concentration, coagulant type and dosage and strength of combined wastewater contributed to the dye and turbidity removal from effluent sample. It was observed that increase in dye concentration causes a decrease in color removal efficiency. This is because the $50 \mathrm{mg} / 1$ dye wastewater sample had higher transmittance values compared to $200 \mathrm{mg} / 1$ dye wastewater sample. The flour wastewater sample also exhibited the same trend. Also, an increase in coagulant dosage lead to increase dye and turbidity removal across all the dye and flour concentration. It was also observed that Coagulants with a higher valence of +3 $\left(\mathrm{FeCl}_{3}\right.$ and $\left.\mathrm{Al}_{2}\left(\mathrm{SO}_{4}\right)_{3}\right)$ had more potent effect on wastewater sample than those with lower valence of $+2\left(\mathrm{FeSO}_{4}\right)$. Moreover, adilution effect was observed during treatment of combined dye and flour wastewater depending on the sample concentration. Finally from the transmittance value obtained at optimum condition $(50 \mathrm{ppm}$ dye concentration, $150 \mathrm{mg} / 1 \mathrm{FeCl}_{3}$ dose), it can be concluded that the coagulation/flocculationtreatment acts as a proper primary treatment process for suspended particles, organics, and color removal. Treated naphthol Green B and flour wastewater showed excellent transmittance and absorbance values and can be reused for processing or production in the textile and food industry.The coagulation-flocculation process can be used as a preliminary treatment while completing the treatment process with more sophisticated technologies like reverse osmosis (RO) to reduce energy and operational cost.

\section{REFERENCES}

[1] A. Matilainen, N. Lindqvist, and T. Tuhkanen (2005), "Comparison of the efficiency of aluminum and ferric sulphate in the removal of natural organic matter during drinking water treatment process,"Environmental technology, vol. 26, pp. 867-876.

[2] Abhiram P., Yung-Tse Hung, Howard H.P. (2020), "Treatment of Combined Acid Black 48 and Coffee Wastewater by Low-Cost Adsorbents". Journal of Environmental ResearchEngineering and Management, Vol. $76 /$ No. 3 /pp. 47-61 DOI 10.5755/j01.erem.76.3.25338

[3] Aksu, Z (2005), "Application of biosorption for the removal of organic pollutants: A review". Process Biochem.,40, 997-1026

[4] Aziz, H.A., Aliaz S., Adian, M.N., Assari, A.H., ZahariM.S (2007), "Color Removal from Landfill Leachate by Coagulation and Flocculation Processes". Bioresource Technology. 98: 218 - 220 .

[5] Bako Myek, Sulaiman O. Idris, and Johnson F. Iyun (2014). Preliminary Study on the Kinetics and Mechanism of the Oxidation of Naphthol Green B by Dichromate Ion in Aqueous Hydrochloric Acid MediumAceh Int. J. Sci. Technol., 3(1): 37-42

[6] BasavaRao, V.V \&MaohanRao, S.R. (2006), "Adsorption Studies on Treatment of Textile Dyeing Industrial Effluent by Fly Ash". Chemical Engineering Journal. 116: 77-84. 42

[7] Booth G., Zollinger H., McLaren K., Sharples W.G.,Westwell A (2000), "Dyes, General Survey". Wiley-VCH. doi:10.1002/14356007.a09_073

[8] Buchhammer, H.M.; Oelmann, M.; Petzold, G. (2001). Flocculation of disperse dyes in effluents with polyelectrolyte complexes. Melliand Int., 82, 104-105

[9] Chen Li, Meihan Zhang, Chengwen Song, Ping Tao, Menghan Sun, \&Mihua Shao (2018), "Enhanced Treatment Ability of Membrane Technology by Integrating an Electric Field for Dye Wastewater Treatment". Journal of AOAC International, Vol. 101, No. 5

[10] F. Renault, B. Sancey, P.-M. Badot, and G. Crini (2009), "Chitosan for coagulation/ flocculation processes-an eco-friendly approach". European Polymer JournaL, vol. 45, pp. 1337-1348, 2009.

[11] Fatah MAA\& Hawash S.I. (2018), "Treatment of wastewater resulted from sucrose, fructose and starch production by aerobic activated sludge process". Int $\mathrm{J}$ Petrochem Sci Eng.3(5):194-198. DOI: 10.15406/ipcse.2018.03.00095,

[12] L Muruganandam, M P Saravana Kumar, Amarjit Jena, SudivGulla and BhageshGodhwan (2007), "Treatment of wastewater by coagulation and flocculation using biomaterials". IOP Conf. Series: Materials Science and Engineering 263032006

[13] Li, X.-F.; Liang, S.-X.; Xi, X.-W., Jia, Z., Xie, S.-K., Lin, H.-C., Hu, J.-P.Zhang, L.-C. (2017), "Excellent Performance of Fe78Si9B13 Metallic Glass for Activating Peroxymonosulfate in Degradation of Naphthol GreenB". Metals, 7, 273.

[14] Liang C., Sun S., Li F.Ong Y., Chung T. (2014),"Treatment of highly concentrated wastewater containing multiple synthetic dyes by a combined process of coagulation/flocculation and nanofiltration". Journal of Membrane Science 469 306-315

[15] M. Y. Wani, N. Hasan, and M. A. Malik (2010), "Chitosan and Aloe vera: Two gifts of nature," Journal of Dispersion Science and Technology", vol. 31, pp. 799-811. 
[16] MadirajuV.H., Yung-Tse Hung, Howard H. P. (2018), "Treatment of Acid Orange 74 Wastewater and Sugar Wastewater by Low Cost Adsorbents". Journal of Advanced Chemical Sciences, Volume 4,Issue 3,Pages 583-585. https://doi.org/10.30799/jacs.188.18040304

[17] Mohamed A. Hassaan\&Ahmed El Nemr (2017), "Health and Environmental Impacts of Dyes: Mini Review”. American Journal of Environmental Science and Engineering, Vol. 1, No. 3,pp. 64-67. doi: 10.11648/j.ajese.20170103.

[18] N. F. A. bintiSaharudin and R. Nithyanandam (2013), "Wastewater Treatment by using Natural Coagulant," 2nd eureca, vol. 4, pp. 213-217.

[19] Nigam, P., Banat, I.P., Singh, D. (2000), "Marchant, R. Microbial process for the decolourization of textile effluent containing azo, diazo, and reactive dyes". Process Biochem. 1996, 31, 435-442.

[20] Pala, A.,Tokat, E. (2002), Colour removal from cotton textile industry wastewater in an activated sludge system with various additives. Water Resource. 36, 2920-2925.

[21] Pearce, C.I.; Lloyd, J.R.; Guthrie, J.T (2003) "The removal of colour from textile wastewater using whole bacterial cells". Dyes Pig. 58, 179-196

[22] Petzold, G.,Nebel, A.,Buchhammer, H.M.'Lunkwitz, K. (1998), "Preparation and characterization of different polyelectrolyte complexes and their application as flocculants". Colloid Polym. Sci. 1998, 276, 125-130.

[23] R. Minke\& U. Rott (1999), "Anaerobic treatment of split flow wastewater and concentrates from the textile processing industry." Water science and technology, vol. 40, no. 1, pp. 169-176.

[24] Rauf, M.A., Shehadi, I.AHassan, W.W. (2007). "Studies on the removal of neutral red on sand from aqueous solution and its kinetic behaviour. Dyes Pig. 75, 723-726.

[25] Sathiyamoorthy M.,Gashaw M., Tesfaye M., Yilma M., Tasew T, Fantahun N (2012), "The Removal of Colour from Synthetic Textile Dye Effluent Using Cellulose Acetate Reverse Osmosis". International Journal of Advanced Research in IT and Engineering, Vol. 1 No.4

[26] Tang S.H\&ZainiM. A.Zaini (2020) "Isotherm studies of malachite green removal by yarn processing sludge-based activated carbon". Chemistry-Didactics-Ecology-Metrology, Vol 24: Issue 1-2.

[27] Tzoupanos N. D. \&Zouboulis A. I. (2008), "Coagulation-flocculation processes in water/wastewater treatment: the application of new generation of chemical reagents". 6th iasme/wseas international conference on heat transfer, thermal engineering and environment.

[28] Yavuz, O., Aydin\&A.H. (2002), "The removal of acid dye from aqueous solution by different adsorbents". Fresenius Environ. Bull. 2002, 11, 377-383.

[29] Zahrim A.Y.\&Hilal N (2013). Treatment of highly concentrated dye solution by coagulation/flocculation-sand filtration and nanofiltration, Water Resource Ind. 3; 23-34 